\title{
Who's on the other side of the table? Power perceptions in construction projects-Thai case studies
}

\author{
SITTIMONT KANJANABOOTRA* (1) \\ School of Architecture and Built Environment, Faculty of Engineering and Built Environment, The University of \\ Newcastle, Architecture Building Callaghan campus, Callaghan, New South Wales 2308, Australia
}

(Received 29 August 2014; accepted 28 January 2015)

\begin{abstract}
Through a lens of power as discourse and using a deconstruction of those discourses, the research identifies the differential perceptions of power and associated roles of the various stakeholders in Thai construction industry projects and how these perceptions of power affected decisions made, and project progress, in three case studies. Results showed that there are differentiated perceptions of power which alter dynamically across the three projects, creating a complex environment of decision-making within each project. Thai construction stakeholders have different perception of power and associated roles in construction projects. Downstream stakeholders such as contractors, sub-contractors and suppliers have perceptions that the owner of the projects has power to control everything in the project, while upstream stakeholders perceive that designers and consultants have more power to control the project. The sustainability and innovation aspects in the project designs often are neglected by decisions made based on financial aspects where power is concentrated with non-technical stakeholders. The perceptions of power that each stakeholder have are different, and whilst there are positive attributes of understanding power, construction projects often end with conflict, resulting in increases in project time, stage delays, poor working relationships, increased costs and sometimes poor delivery outcomes.
\end{abstract}

Keywords: Power and project management, power discourse, power relationships in construction projects.

\section{Introduction}

This paper extends previous research about power in construction projects by (Pinto 2000; Sage and Dainty 2012; Cashmore et al. 2014). Much of this literature focuses on the negative effects of problems created by participants in construction projects negotiating 'who is in charge' or 'who has the right knowledge'. These are contexts of contested power relations between those participants. However, whilst Walker and Newcombe (2000) show that there can be a positive use of power in construction projects, there is an argument that the building decision-making process has to be dynamically aligned with the stream of information available at that time (Clegg 1992) and this is associated with who has significant power to either influence or control any of the nature, extent, complexity or progress of a project. Decisions have to be derived from relevant elite stakeholders who are involved in construction projects (Harquail and King 2010; Sage et al. 2010; Love et al. 2014). Previous research has identified that decision-making processes in project management are related to, and affected substantially by, stakeholder's power (Pinto 2000; Sage et al. 2010; Cashmore et al. 2014) and the relationships among stakeholders (Cicmil et al. 2006). The coherence among stakeholders and the way that they influence each other also have an impact on how decisions have been made in construction projects (Oliomogbe and $\mathrm{J}$ Smith 2013; Chou and Ongkowijoyo 2014). This research identifies the differential perceptions of power and associated roles of the various stakeholders in three Thai construction industry projects and how these perceptions of power affect both decisions made and project progress. These three multi-million dollar projects involved construction of two hotels and one large shopping centre over a build time of between 3 and 5 years.

\footnotetext{
*E-mail: sittimont.kanjanabootra@newcastle.edu.au 


\section{Research context}

Power in a human sense is often defined simply as the ability to influence others, or specifically to alter the 'rights' of others, often without consent (Hohfeld 1917). Boulding (1990) mentioned that without human valuation and human decisions, the term 'power' is a concept without meaning. The other type of power, so-called 'power of appointment' or 'power of attorney' refers to the specific 'rights' that have been created 'in the person to whom the power is given rights in terms of proprietary character' (Hohfeld 1917, p. 727). Power has also been used as a medium to enable or constrain particular patterns of actions, the notion of control (Marshall 2006). Power can also influence the outcome of the project (Austen et al. 2008).

Clegg (1989) argues that the production and organization of power have three forms: the episodic, dispositional and facilitative. The episodic represents the irregular but operational exercise of power as stakeholders in social or organizational contexts deal with communication, conflict, their feelings and resistance or contestation in their interrelations. This reflects what happens in most construction project organizations where stakeholders engage by using available information, materials, techniques and strategies to negotiate their way through different encounters and different time frames along the project (Marshall 2006). The dispositional is a socially constructed element that informs relationships and allocates legitimate authority. The facilitative is grounded in the social context of a situation, sometimes in positional structures, in the design of tasks and in socially formed networks of people and institutions.

Mitev (2001) and Cashmore et al. (2014) argue for 'the inclusion of broader social, economic, political, cultural and historical factors' (Mitev 2001, p. 84) and therefore adopting a Foucauldian perspective on power. By taking this approach, they argue, we can enable a better understanding of the power and politics involved in construction projects, by focusing on social issues, interrelationships and social structures. These are social relationships which Weber (1978, p. 26) defines as:

the behavior of a plurality of actors insofar as, in its meaningful content, the action of each takes account of that of the others and is oriented in these terms. The social relationship thus consists entirely and exclusively in the existence of a probability that there will be a meaningful course of social action, irrespective $[\ldots]$ of the basis for this probability.

These social relations therefore include organizational operational relations (such as regulations, delegations and chain of command) of a project. They exist within the social construct that is an organization and are inclusive of power, conflict and communication. In another perspective, Foucault (1977, 1978, 1980), argues that the analysis of power relations is fundamental to understanding social relations and our knowledge of the world and ourselves. He argues that social relations and power cannot be separated. Foucault focuses on what lies within social relations based on knowledge rather than the 'social' structure that is represented, which Weber see as the key. In this research, the focus is on the role of power within social relations and whilst not rejecting Weber, the research is more grounded in the ideas of Foucault.

Rather than taking the social aspect of power relations in construction projects at face value, we need to understand and perform research that recognizes the complexity and historical construction of the members of the implementation team and process (Mitev 2001). We currently cannot describe or explain the political environment because politics endures influence, pressure, dogma, expediency, conflict, compromise, intransigence, resistance, error, opposition and pragmatism (Ball 1990); that is, it is a complex, messy, inconsistent and ambiguous construct, full of dilemmas for participants (Corbitt 2000). We can ask about that complexity, ambiguity and messiness because they relate to the social realities imposed in organizations and these realities are essentially informed by power and politics. By using such a critical path in research, we can expose a better understanding of the processes in construction management by providing rich descriptions about human behaviour, specifically about the power and politics involved. Critical studies expose political agendas, power coalitions and discourse. However, they offer no solutions, but rather they identify what is happening to raise the consciousness of others (Peszynski and Corbitt 2006).

The concept of power relations, as proposed by Foucault $(1977,1978,1980)$, has been utilized in research in order to identify the dynamic nature of human relations through the influence of power and politics. Foucault (1978) argued that power is a dynamic set of relationships constantly changing from one point in time to the next. It is this recognition that is lacking from most studies in project analysis in construction management. Furthermore, these power relations are created through the use of discourse. Discourse represents meaning and social relationships, forming both subjectivity and power relations. Discourses are also the practices of talk, text and argument that continuously form that which actors speak. Rather than viewing power as episodic and structured, as the traditional view of power is, Foucault theorized another view of power, as both an obvious and hidden, as 
dynamic and changing, as socially determined, and as an agreed position taken in a social context, providing the researcher with a lens through which the nature of the power relationships is perceived by others and interpreted by the researcher. Power relationships here constitute the nature of the relative positioning of each stakeholder involved, expressing their position, their extent of influence and their conceptualization of control through both their own understanding and that particular social groups understanding of the prevailing discourse.

Power is here seen as constructed in social contexts and manifests its influence in all social contexts (Corbitt 2000; Corbitt and Thanasankit 2002; Nguyen et al. 2006; Peszynski and Corbitt 2006). Construction projects are social contexts where power is constructed and social relations emerge based on that constructed power. These relationships are grounded in elements of domain knowledge (Kanjanabootra et al. 2013) and in spheres of influence in construction projects, which relate to the various stakeholders: owners, investors, architects builders, designers, engineers, and so on. As the stakeholders interact in the context of a construction project, their degrees of influence change throughout. However, contestation is also normal in power contexts. Contests over control and influence are normal representations of power and often result in either disruption in the social environment, or negotiation and compromise, or inform the development of new power relations through an iterative process, which keeps the social context dynamic (Corbitt 2000).

In this research, the stories of power relations in the three Thai construction projects are interpreted through this lens of changing power relations and the contexts of influence and control expressed as discourse, accepting that:

(a) stakeholders are persons or groups with legitimate interests in procedural and/or substantive aspects of corporate activity. Stakeholders are identified by their interests in the corporation, whether the corporation has any corresponding functional interest in them. (b) The interests of all stakeholders are of intrinsic value. That is, each group of stakeholders merits consideration for its own sake and not merely because of its ability to further the interests of some other group, such as the shareowners. (Donaldson and Preston 1995, p. 67)

Stakeholders in this research included clients (owners), project managers, engineers, designers, architects, contractors and suppliers. These interpretations are also made here within the Thai cultural context.

Hofstede (1980, 1997, 1998, 2001) Hofstede et al. (2002), Hofstede and Hofstede (2005) argued that culture represents the constructed meaning of the way people behave in social contexts. He showed that these behaviours are modified in each cultural context according to five dimensions: power distance, individualism versus collectivism, masculinity versus femininity, uncertainty avoidance and degree of long-term orientation. Alternative but similar interpretations of culture by Hampden-Turner and Trompenaars (1997) and Corbitt et al. (2004) vary the dimensional framework, but offer a similar, repeated argument that each local culture differentially influences the behaviour and that these differential patterns of culture and behaviours can be identified and act uniquely in their social context. New dimensions were added by Hofstede et al. (2010), namely indulgence versus restraint and pragmatism versus normativism.

Thanasankit (2002), Thanasankit and Corbitt (2000), Hanisch et al. (2001), Jirachiefpattana (1996) and Corbitt et al. (2004) have applied these constructs in research in the Thai context, not about construction, but across a variety of technological, social and business contexts. Their research shows that Thai culture significantly impacts on the way people relate in their social contexts, impacting on their social relationships. Their research concluded that Thai culture is significantly hierarchical where those in senior positions are considered 'right'; there is a large power distance between levels of authority and position; power often lies with ownership of resources, as that ownership provides the right to determine what will happen and make decisions; behaviour is deferential to seniority, those perceived to be in lesser positions relative to others are seen as less important; this is mostly due to the need for certainty. The socialization of groups is very important. Groups operate 'together' for the benefit of all involved; it is highly collectivized and 'feminine' in the Hofstede context where there is more respect and communication rather than being commanding and conflict ridden. Thai culture is influenced by 'who knows who'. Knowing another person or group who are part of another group impacts often on who becomes involved in social behaviours, in business and therefore in construction projects. Thai culture is essentially pragmatic and a culture of restraint with a short-term orientation.

\section{Research design}

This case-study research applied an interpretivist approach to analyse collected data using 'evidence gathering techniques that are focused on the intention and subjective meaning contained in social actions' (Gerring 2007, pp. 69-70). Interpretivism is a research paradigm that supports the importance of understanding human behaviour with an emphasis on the 
comprehension of human action and knowledge embedded in a social construction rather than the forces which shaped that action (Dainty 2008; Hanisch 2009). Interpretivist research assumes that there is a 'difference between the object of natural science and people in that phenomena have different subjective meaning for the actors studied' (Dainty 2008 , p. 3). This approach accepts that 'human behaviour is mediated by meaning and seeks to identify types of process and their expression in particular context' (Schweber and Leiringer 2012, p. 484) in their own subjective frame of reference (Williams 2000).

Case-study research investigates contemporary phenomena within its real-life context, especially when the boundaries between phenomena and context are not clear evident' (Yin 1994, p. 13). Case studies are also relevant techniques to use to study social phenomena in a single setting to help researchers answer 'how' and 'why' questions of social situations that involve behaviour through descriptive or exploratory research (Stake 1985), and provide insights and ideas of specific phenomena such as what happened during the construction projects (Fellows and Liu 2008). The interview questions were focused on power relations between all stakeholders in construction processes in each case study, focusing on 'power' which can be expressed in both positive (successful execution) and negative (dispute) ways (Sage and Dainty 2012). In this research, the aim was to uncover changing power relationships to discover what was happening in the projects and therefore how the relationships were emerging. To this extent, the interviewer asked respondents about the nature of who had control in the project and how this changed during the process.

Two of the projects were hotels and one was a shopping mall, and in these cases, it was reflective analysis on what had happened, in the context of each interviewee's perceptions of theirs and others power and the relationships on the social communities of each construction project.

\section{Case details}

The interviews were conducted with 18 practitioners in 3 case studies of large-scale construction projects in Bangkok. The rationale behind the case-study selection is that the characteristics of Case Study project A (large scale retail building) is different from those of Case Studies B and C (residential building). The data were collected from key stakeholders in each construction project. The interview with each stakeholder lasted between 30 and 45 minutes (Table 1). Each project was developed on a design-bid-build delivery method. Each of the three case studies did not employ building information modeling technology or methodology or integrated project delivery. Auto-CAD and paper

Table 1 Case project characteristics and participants

\begin{tabular}{|c|c|c|}
\hline Case study & Description & $\begin{array}{c}\text { Research } \\
\text { participants }\end{array}$ \\
\hline \multirow{6}{*}{$\begin{array}{l}\text { Case Study A } \\
2012\end{array}$} & - A large-scale retail business & 1 Owner \\
\hline & - Project developed by owner & 1 Engineer \\
\hline & - Design by international architect firm & 1 Contractor \\
\hline & - Used international design engineering firm & 1 Supplier \\
\hline & - Used international contractor company & - \\
\hline & - Used design-bid-build contract & - \\
\hline \multirow[t]{6}{*}{ Case study B 2011} & - A high-rise hotel and service apartment project & 1 Owner \\
\hline & - Project developed by owner-an international property developers company & 1 Project manager \\
\hline & $\begin{array}{l}\text { - Design by international architecture firm and local architecture firm for detailed } \\
\text { design }\end{array}$ & 1 Architect \\
\hline & - Used international design engineering firm & 1 Engineer \\
\hline & - Used international contractor company & 1 Contractor \\
\hline & - Used design-bid-build contract & 1 Supplier \\
\hline \multirow[t]{7}{*}{ Case study C 2010} & - Multiple building hotel construction & 1 Owner \\
\hline & - Project developed by Thai owner & 1 Project manager \\
\hline & - Design by international architecture firm & 1 Architect \\
\hline & - Used international design engineering firm & 1 Hotel operator \\
\hline & - Used local contractor company & 1 Engineer \\
\hline & - Used design-bid-build contract & 2 Contractors \\
\hline & & 1 Supplier \\
\hline
\end{tabular}


Table 2 Data analysis nodes

\begin{tabular}{|c|c|}
\hline Nodes & Example of words and phrases coded in node \\
\hline - Control by Owners & But that's all we can do because owner 'has more power' to make decision \\
\hline - Control by Architects & $\begin{array}{l}\text { We are 'unwillingly' keeping it in our stock and hope that it can be modified } \\
\text { and use in other projects }\end{array}$ \\
\hline - Control by Project Manager & $\begin{array}{l}\text { Owner 'allows' tenants to do things different from design criteria otherwise } \\
\text { they will not rent the space }\end{array}$ \\
\hline - Control by Engineers & $\begin{array}{l}\text { Owner also 'have been pressed' by bank or sometime shareholders in case of } \\
\text { public company }\end{array}$ \\
\hline - Control by Contractors & - \\
\hline - Control by Suppliers & - \\
\hline - Control by Finances & - \\
\hline - Control changing from issue to issue & But because the design 'keep changing' all the time, we 'have to follow' them \\
\hline - Control changing from stage to stage & $\begin{array}{l}\text { I'm talking about who give 'most benefit on that specific issue' back to me the } \\
\text { most 'I choose to trust' that person and make decision based on that }\end{array}$ \\
\hline - Control by Standards, Laws, Regulations and & Not really most of the time is technical aspects and 'then' money \\
\hline Project Characteristics s & Our technical requirements are 'more important' than theirs \\
\hline
\end{tabular}

documentation formed the basis of each project's operations. In Case Studies B and C, there was a continued history of the owners in both case constantly changing requirements. In Case Study $\mathrm{A}$, the owner also changed requirements constantly but in response to the changing needs of those who were going to rent the retail spaces. All of the projects were delivered overtime, behind schedule from six to nine months. Budgetary information was withheld for commercial-inconfidence reasons.

\section{Case-study data analysis}

The data were derived from semi-structured interviews, conducted as conversations between the interviewees and the researcher who had relevant industry. The conversations were allowed to flow according to the emergent stories. This was important as the data being sought were about their perceptions of how power was constructed and how it changed over time. Since there were a number of stakeholders involved in each case study, it was necessary to identify the differing perceptions of who was in charge, who had power and how it changed. The conversation notes and transcripts were coded with NVivo (Bazeley and Jackson 2013), using tags from empirical studies, categorizing text into defined themes using an abductive (iterative) analysis. The result is themes which reflect how stakeholders perceived 'power' and making sense of these perceptions, informed by literature (Ibrahim, 2013).

The NVivo analysis utilized various nodes, each informing the researcher about perceptions of power and power relationships. The search was not about referencing of the word 'power' per se; rather it was a search for relationships and perceptions about who had control and at what stage. This in essence is demonstrative of interpretivism as the researcher interprets words like 'control', 'forcing', 'allow' as representative of how these power relationships form scenarios embedded in the stories told by the participants. Some examples of the nodes created in NVivo and the key words and phrases that were identified in the texts of the interviews/conversations with participants, that are reflective of 'power' or 'power relations', are shown in Table 2.

These nodes were used to reflect on the nature of the social relationships that existed in each project and provided the basis for the researcher to interpret the texts to see how power was perceived and how it was reflected in each project's operations.

\section{Research findings}

\section{Thai construction stakeholders - different perceptions of both their power and associated roles}

The individual stakeholders often perceived that others have more power to control the projects than they have. Within the Thai context of this research, the Thai respondents used the word (อำนาจ um-nard) for power which in their understanding and usage is the precursor to control, based on the 'widespread' impact of power distance in social settings such as organizations. Power in their context determines control. For example, downstream stakeholders such as contractors, sub-contractors and suppliers have perceptions that the client (project owner), architects and consultants have 
power to control everything. While upstream stakeholders such as owners think that designers and consultants have more power to control the projects. In their view, these different perceptions of power have different impacts on construction projects. These are not different perceptions of control, but rather of power alone as control has only one meaning, one derived from power in the Thai context. Some stakeholders think that architects have power to control what actually happens in construction projects and how designs are modified to work. An engineer from Case Study C said:

I think it is the architect who has power to control the project, because I think $\mathrm{M} \& \mathrm{E}$ work is the end of the line. How the building looks and functions have already been set up before you start your process. So in my job the power to control things is with the Architect. I have to fit all of our systems (M\&E provision) into their building design (allocated space). Most of the time my work conflict is against the architect not the owner. We never force them (architect) to change their design. But they don't understand the nature of engineering systems, we need space to accommodate the system which is just given to us ... .

The impact was that the engineer had to redesign the M\&E provisions. The socially constituted nature of power here was one where relationships were hierarchical and one stakeholder appeared to be subservient to another. Discourse was constructed by the architect and followed by the engineer. The social relationships inherent in the project determined the nature of this power. In the same Case Study C, one stakeholder disclosed a situation where the social relationships became complementary based on social action and mutual beliefs in Feng Shui. ${ }^{1}$ One of the suppliers mentioned:

I think that in the overall picture the architect has most power to control the project. Some senior architects can convince owners to follow their comments. I have seen in one project (not this case study C), the owner is a famous Chinese businessman who has quite a strong personality. However, the project architect, who believes in Feng Shui (the Chinese art of placement), had a long conversation with this owner and managed to convince him to change a major part of the building design to align with Feng Shui and thus his design.

In Case Study B, sets of relationships were identified that enabled those with domain knowledge to take responsibility for their areas of expertise. One of the architects said:

I think it varies from project to project. Who has power to control a project depends on that particular project's organizational structure. In this project the owner has boundaries. They let team members have power to control issues based on their roles and responsibilities, including how the building looks, but the architect has ultimate control on that; while with technical stuff it has to be the engineers.

These three examples highlight firstly, that 'power' in these projects results from social relationships that serve to discipline people by a command process which determines what can and cannot be said, and who can and cannot make decisions; and secondly, what to some is 'obvious' and to others is 'hidden'. A lack of understanding of, or an inability to see the 'hidden', forms voids which determine what can be and is said, discourse, in a construction project. This non-identification of the 'hidden' can lead to negative impacts on the work of other stakeholders. For example, some architects are concerned only with visual aspects of the construction project and often use this as their discourse to control both the project and other stakeholders involved. The impact that it has on the project is that some technical or engineering aspects such as performance of the building have to be compromised because of the continual discourse about the 'visual aspects of the building'. Owners involved in both Case Studies B and C mentioned that using international architecture firms with famous architects in the project can give both positive and negative impacts, as their expertise is to design 'how the building should look' and everyone respects the architect's role and responsibility in that design. However, sometimes, these famous architects are not happy if other stakeholders (even an owner) ask them to change or revise their designs for any reason. Therefore, it becomes a little harder for everyone else to work in the project. The discourse of 'design' in the three Thai case studies became paramount and determined the roles and functioning of the other stakeholders and often became the focus of conflict between stakeholders as the necessities of functionality challenged the dominance of the design discourse with another discourse of 'making it actually work'. There was in effect a web of social relationships where the stakeholders collectively determined the levels of control of each. In addition, there was evidence of that discourse of design being challenged by a perceived superior discourse of ownership, often too, challenging the relationship between owner and architect.

In some cases, it depended on the type of project, for example, an engineer in Case Study A said:

I think it depends on the type of project. If it is a residential project they (architects) often have more power to control the project. However, if it is a 
factory type of project where technical requirements are more important than how it looks, we (engineers) have more power to control the project.

A different perception that emerged in the case studies was that some stakeholders believed that project managers have power to control the construction project. A supplier involved in Case Study A said:

Sometime I also think that the project manager has power to control the project. We often don't know what discussions they have had with the owner. Sometimes the owner makes decisions against our technical recommendations and they choose cheap options. At the end of the day, if that is what they hire us to do (to give recommendations) so we did our job already.

However, the project manager in Case Study B noted:

I think it is us (project manager). We have to be able to control the project to finish within the agreed time frame and cost. Sometimes when I encounter owners who are only concerned about money, I have to counter and try to convince them with project technicality and have to show them that cheaper is not always the answer. Sometimes I also have to fight with designers and contractors to maintain optimum benefits to the owner. This is what they hire me for which is to manage the project. So I have to use power by reasonable means so that I can gain control of the project.

The main concern of the project managers was the functioning of the building whilst the owner focused on financial aspects. Project managers see functionality as more important in this contestation, inevitably leading to conflict. The differential perceptions of power and control and the different discourses being used between stakeholders in these Thai construction cases reflect apparent conflicting discourses, often resulting from non-recognition of the 'hidden' discourse of that project, that is, who has the determined control. In some cases, it was clearly the owner, in others, the architect. However, throughout the projects, the discourse changed because problems emerged and specific domain knowledge was required to solve problems. In these instances, the 'power' reverted to another stakeholder in the social web of the project. If that did not occur, and this was identified as happening quite often, then negative consequences developed in that project such as cost overruns and time delays.

Many stakeholders believed that finance has power to control construction projects. The discourse of 'financial viability' often became the mantra of control and determined the course of action, often as a result of decisions made by the owner or a leading architect or project manager. An engineer from Case Study C said:

'I think contract and specification of the project are important. In the end, the project has to finish and run the way it is supposed to. The other factor is time. In a business context, time equals money. If I have to start the factory on this date, it means that it has to be this date and cannot be delayed.' $\mathrm{He}$ added: 'I think it is money, as a driving force behind the owner and project manager.' This is Thai construction industry culture 'Time is money, money is time.'

However, in contrast to this view, the project manager from the same Case Study C said:

From my view, the owner doesn't really have power to control the project. Owners are pressured by banks or shareholders. So they have to make every decision based on time, the quicker, the better. They use estimate figures to make decisions. It also depends on how much risk they can take in particular issues. So that's why they don't need accurate information in the design. They just work based on information from the conceptual level. Detail design information doesn't really mean anything to them (owners).

One owner from Case Study B added:

Money and return of investment is power behind people. There are many times that decisions were made based on financial aspects alone....

The stakeholders in the three Thai construction projects showed that decisions in those projects were made in a majority of instances based on financial aspects, a discourse of money and enabling control by owners. Often sustainability, energy sufficiency or high-efficiency building designs were not used in many construction projects because they were more expensive. In some cases, engineers provided sustainability study reports to clients to demonstrate all kind of benefits. However, return on investment was seen by owners as being too long, therefore owners were not interested. This financially driven mindset, discourse, was a major motivation for property development investors in Thailand, decisions being made based on financial aspects where power is concentrated with non-technical stakeholders. Thai culture, as mentioned previously, is rather pragmatic with the best/quickest/cheapest solutions being preferred. Sustainability is seen as an indulgence, in the cultural sense, and is thus likely to be overlooked except where government regulations 
proscribe action. There is no overt discourse of sustainability generally across the construction industry in Thailand at this time.

As a result of the differential discourses, the way they changed as problems emerged in the projects and the contestation over power and control in the Thai construction projects, three key effects on the projects themselves were identified by the interviewees:

- Construction projects were delayed, increasing costs;

- Engineering designs had to be revised, adding time and extra cost; and

- Some difficult stakeholders created a nuisance type, working atmosphere, adding further delay and increasing costs. In Case Study C, the owner played by strict rules, in that everything had to be exactly as in the specifications of the project. However, he lacked flexibility in situations where the architects and engineers had to make pragmatic decisions to enable problems to be solved and the construction process to move on. In Case Study A, the project requirements were never settled before construction because the users of the space were not settled and their requirements kept changing, so the engineers and architects had to add margin into the design which made the quantity surveying less accurate. The literature generally supports a view that such instances are more common than not (Zou et al. 2007).

\section{Impact of traditional design-bid-built procurement process}

At the design stage in the Thai construction projects, the suppliers of materials were not involved; as a consequence, the decisions made in design were often inaccurate, but suppliers had very limited power to get involved and provide more accurate information. This affected implementation and increased the potential of poor quality in the construction and often led to increased rectification. The lack of power of suppliers in the design process often meant that they had to supply products that were different from the design as control rested with building owners, engineers and architects and they had made decisions based on incomplete information, often without consultation. This happened because, during the design stage, design engineers do not know which suppliers will be awarded the contract for work and which products are going to be used in the project. Therefore, engineers can only provide general design guidelines that products from various suppliers can fit the design. As a consequence, the design is not fully open for competition.
There is incompleteness in the information limiting the effectiveness of the design, created by a discourse of a design-bid-build approach adopted in these three cases studies. This accepted practice itself is a controlling discourse hampering design and the effectiveness of downstream stakeholders in the construction process, being required to accept the dominant role of the design architects and engineers, and the financial discourse of the owners. One contractor from Case Study C said:

I think sometimes the process itself makes it difficult to control things. For example during the construction period we have been forced to carry on construction while the information is not complete. But because we are the end of the supply chain we just have to go with the flow. There were a lot of design clashes on site. To prepare an RFI (request for information) or an RFA (request for approval) and send it through procedures to the PM then to consult and then get back to PM and then back to us, sometimes it's too late. Onsite can't wait that long.

In Case Study B, the architect involved added:

There are some designs that have changed due to unforeseen circumstances with procurement. But it still depends on the role of relevant stakeholders. For example when we did detailed designs we had chosen one type of material for the façade system, but when the construction began the contractor for some reason was unable to acquire the material that we specified in our initial design. I think there's something to do with the market at that time. So we had a meeting with the owners and suggested to them that if you want to use the initial option it will be very expensive but aesthetics wise it still remains the same, but if you change to another material, we might have to compromise aesthetics a little but it will be a lot cheaper. Then the owner had to make a decision.

In this case, the impact on the project was that the construction process had to be delayed because the supplier had to provide 'requests for approval' documents and send them through project communication channels via the project manager to the design engineer who then had to review and send approval through the same channel. In parallel, another request for approval in terms of financial variation (from original designs) also has to be carried out. Sometimes, just to get one variation approved took at least a week due to all these documentation processes. In the Thai context, such short time frames are normal as Thai culture focuses 
on short-term solutions as discussed above. This is in contrast to non-Asian projects where these processes can and do take considerably longer (Walker and Shen 2002; Love et al. 2010).

The discourse around process itself created contestation between stakeholders and challenged the overriding discourse of financial parameters. Suppliers believed that they had limited power within the social construct of the project to control anything in the Thai construction projects. They believed that their positioning at the end of the construction value chain meant that they received a lot of pressure from other stakeholders. In essence, they were the receptors in the social relations of the project of what Foucault termed discipline in the web of relationships constituted by the stakeholders where deference emerged, differentially throughout the project, to the owner, to architects, to engineers and/or to project managers, and often to combinations of them, where domain knowledge was needed to resolve issues. In Thai culture, according to Hofstede's theory and from Thanasankit's research, there is significant 'power distance' between those in authority or senior and those who are in lesser position. One of the key behavioural practices recorded and observed by Thanasankit (2002) was that subordinates always deferred to their seniors. Often this meant that there was acceptance of the opinions and decisions of the seniors without question. Suppliers often got involved in these Thai construction projects when all design was done and this limited their opportunity to provide input to the design process. One supplier in Case Study A added:

Many times, I encountered problems about designs when we got the job. I have been in this business for more than 10 years. I worked with other brands before. A difference in term of specifications and characteristics of products in a similar range among various brands are not significant. We know that, but I don't think engineers (designers) know the products right through, like us. So, when they design, sometimes they design the right application but they specify the wrong products.

\section{A supplier in Case Study B also said:}

We know only there are some changes in the project. One part of the building has been put on hold and awaits revised information during the construction stage but we don't know the reason. These changes won't impact us if we haven't started our production. But if we have already started it will impact us ... This kind of error sometimes cost us a lot of money. However, sometimes we have had to accept it and get the job done and hopefully get the next project with them.
Suppliers had to be aware of uncertainty in the projects. The differing perceptions of power and who had control also had an impact on how some stakeholders conducted business in relation to others. Downstream stakeholders such as sub-contractors and suppliers often put up with more pressure in the Thai projects, as they hoped that being obedient to upstream stakeholders might bring them access to future projects. Suppliers were essentially 'disciplined' by all other stakeholders, mostly owners, engineers and designers. For example, in Case Study A, the design engineers determined that the capacity of the air-conditioning machinery was to be $2500 \mathrm{kw}$, knowing that only one supplier was able to meet those conditions. The engineer then was 'choosing' the supplier and rejecting other suppliers, based on their own domain knowledge and preferences. Suppliers had to meet those needs and maintain those relations to continue to gain access in this way to fulfilling project technical requirements. In Case Study C, the design mechanical engineer had a specific problem with a particular room and its needs for air conditioning and found a particular supplier was able to meet that demand. However, that brand suppliers did not win the contract to supply and the winner was not able to supply the product. Normally, this would require customization/made to order which was going to take too much time. So changes had to be made and a pragmatic solution, in the Thai context, was arrived at.

The discourse of those with financial control and ownership dominated with respect to the construction method adopted in each project. The contestation within the social relations identified in this analysis, contest over control based on expertise and design, added to more complicated power relations in these Thai construction projects, again adding time, increasing costs and delaying completion. However, the maintenance of project continuity was a key positive effect of these processes enabling project momentum to be maintained, albeit at some loss across the project. Again, this relates to construction projects being a negotiated task with give and take. Any negotiation is not zero-sum and therefore in all of these projects, whilst there is the positive effect of maintenance of momentum, there is the negative effects of costs being re-allocated, or projects costs being affected by time overruns.

\section{Impact of project characteristics, specifications, building codes, regulations and the Thai building law on power relations}

Many interviewees mentioned that power to control the project often related to the parameters around decisionmaking processes, controlled by laws and regulations 
and a discourse of the State. An engineer from Case Study C said:

I think sometimes that laws and regulations have power to control the project. Sometimes we just have to do things that we don't want to because of regulations such as car parks per number of residences, green area in proportion of overall area, or technical issues, for example an IT center with a raised floor; the regulation said, if you raised the floor higher than $100 \mathrm{~mm}$ you have to have a smoke detection system. We don't want that because it costs a lot of money, so we have to try to push the raised floor level down, but we also can't because the IT system accommodates all that space already.

In all of the Thai construction projects, the project's functionality, code and regulation characteristics and project specifications were the basic logic that shaped specific characteristics of the buildings. However, the participants discussed how they manipulated their way around these regulations and laws, albeit minimally but necessarily, to enable project completions, often adding additional cost. The Thai cultural context has been shown already to be fundamentally pragmatic and one where there is significant attention to uncertainty avoidance. The Thai owners, engineers and architects in these three case studies often referred to the need to be certain about what was happening. However, the researcher notes that often in the design process, any or all of these same stakeholders were often uncertain and deferred their decisions 'upwards', a common issue in Asian cultures (Thanasankit 2002). Manipulation and work arounds were necessary pragmatically and not reported. They were just done. The discourse of law and regulation imposed by the State added a third layer of discourse imposition on stakeholders, creating situations where the discourses challenged the expertise discourse of architects, engineers and suppliers, and the financial discourse spoken by the owners.

However, there is also evidence that power relations can have a substantial positive effect in social groups. Walker and Newcombe (2000, p. 38) added 'a balance pursuit of self-interest and interest in the welfare of others; viewing situations in win-win (nonzero-sum) terms as much as possible; engaging in open problem solving and then moving to action and influencing'. Lindebaum and Fielden (2011) argue that in construction projects, power is reinforced by the social structure of ownership and stakeholder relationships and therefore by the position held in the project which, Brass and Burkhardt (1993) argue, produces positive effects. These Thai case studies demonstrated that even the same stakeholder (project manager) or owner can make different decisions about the same issue in the context of any construction project and produce positive outcomes. There is no self-evaluation by the participants to indicate who or which decisions are right or wrong. The data simply highlight the existence of differing, and at times, conflicting discourses, constructed by stakeholders based on their own perception of their roles and enhanced by the relative and differential perception of other stakeholders, despite structures.

In Case Study C, there was a clear example of how the power relationships changed. Initially, the design was controlled by the owner and architect and the architect played a key role up to a point early in the construction process. At that stage, the project manager identified many design problems that had ignored sound engineering principles and these were going to have severe financial impacts. As a result of discussions between the project manager and the owner, the architect was excluded, what Foucault would see as 'punishment', and the discourse changed from one about design to one which incorporated both financial and engineering aspects. The project manager said:

I had to take this action and had a 'behind the curtain' discussion with the owner to gain control of the project. Otherwise the construction process would stop and as a consequence delay project delivery. I knew that the architect was not happy, but if I had not done this, the project would have cost too much.

The owner believed that he was entitled to use his power to ask architects and engineers to do more collaborative work during earlier stages of the project. The technique used was to demand more frequent design meetings, with the owner supporting most additional expenses. They believed that to get designers from all parties to work together and get them to really understand requirements of the project, conceptual design was crucial. The owner said: 'This is the fundamental of the project, if we all get it right at the start, there will be less problem later in detail design and construction phase'. The result was continuity of the project, keeping the project on track overall-someone though could be unhappy as it was not a zero-sum game.

\section{Discussion}

The analysis of the three Thai construction project case studies shows that there are conflicts of interest among stakeholders over control within the projects. Their understandings of who, in the social construction of the projects, has power to control the project, either individually or collectively, is often based on 
perceptions that other stakeholders, or groups of stakeholders, have more power than them in an organizational construction project hierarchy, often contradictorily. In these Thai projects, the differential perception of where power was constituted varied. In some cases, the groupings of domain knowledge workers with expertise were able to influence decisions based on their knowledge; at other times, such knowledge was excluded because a prevailing discourse of financial constraints was imposed by the project owner, and/or by the project manager. The 'web of relationships' in these projects determined the discourse driving the project and thus the power relations that existed.

The research showed that over time, these relationships could change and a new set of relationships emerge which changed the discourse, either in part, or for some limited time. In the organizational structure of Thai construction projects, contractors and suppliers perceived that clients, architects, engineers and project managers had power to control them. This power can be in a form of 'power of attorney' (Hohfeld 1917) or was embedded in allowing or not allowing some stakeholders to get the job and become a member of the project team. This structure was also interconnected with the design-bid-build procurement methods used in the Thai projects, often limited to owners and project managers. Other players are then incorporated, but they are controlled. Contractors and suppliers are never included in this relationship and thus are stripped of any influence in decisions made. This type of procurement limited the involvement of the downstream stakeholders such as suppliers of products, essentially through their exclusion in the design process which was controlled by owners financially, and at times by architects and by engineers. Therefore, downstream stakeholders had to 'be obedient' by offering only support such as technical information, business discounts, products availability and faster product delivery to owners.

Cicmil et al. (2006), Clegg (2006); Clegg et al. (2006), Sage and Dainty (2012) argue that since power and knowledge are intertwined, then a person who holds knowledge should be able to use knowledge as power to control situations. Foucault (1980) argued that 'knowledge is power' and with an imbalance or conflict over knowledge, then the power is distorted. Such a view is indicative of an information asymmetry (Akerloff 1970) in the construction project which, he and others including Spence (1973) and Nayaar (1990) argue, can be problematic for both parties and lead to a possibility of loss on both sides, a less than satisfactory economic position in a construction project. The three Thai case studies show that in the Thai construction industry, financial considerations, a discourse of money and risk, were one of the factors that enabled control of construction projects, through the power roles adopted by owners. On many occasions in these Thai case studies, stakeholders such as engineers, contractors and suppliers used 'technical knowledge' to demonstrate benefits and advantages for the construction projects. However, this knowledge was often ignored or neglected and instead the decisions were made based on 'money' only because options were perceived to be too expensive. There was a contest between the discourse of money and the discourse of expertise. This in essence represents an information asymmetry in that context. This was exacerbated in the case studies when owners withheld information and further distorted the balance of power. Financial aspects empowered some stakeholder's rights to make decisions or control construction projects. Return on investment was the most influential discourse in all three Thai construction projects. Power in these specific cases seemingly became less attached to holders of technical knowledge because to make financial profits from construction projects was the dominant discourse and informed where power was located in the social structure, with the owners. This part separation, it can be argued, from those with technical knowledge (architects, engineers, designers, quantity surveyors and product suppliers) is a consequence of the information asymmetry created. Without the expert knowledge of the technicians involved in the construction process, there can be no project, so there cannot be complete separation of power and knowledge across any construction project. The degree to which power or knowledge is dominant becomes affected and this reflects the asymmetries created by those making decisions with the power of control. However, there is still power held in those with expert knowledge and they are essential. The reason for this apparent power and knowledge separation perhaps could be the culture of industry practice in the Thai construction industry. The existence of a large 'power distance' in Thai culture fosters these asymmetries because the one at the top has control and those below must adhere without conflict, a state of conflict avoidance, typical in Thai contexts. Whether similar situations exist in all construction contexts in Thailand is itself uncertain and further research needs to be undertaken on this for clarification.

Participants from the Thai projects mentioned that the desired working environment in a construction project is when building functionalities (project characteristics) are the driving 'power' that controls the projects. They argue in the social structure that constitutes a construction project that builders and suppliers should have more power to influence design, rather than the existing nature of the power relationships where they are excluded. Therefore, when problems occur, a project team can use knowledge to 
solve the problems without having to be concerned that their solutions will upset anyone. This makes the working environment desirable, in their opinion, and construction projects can run smoothly. However, this rarely happened because each construction project team was a collection of stakeholders who joined the team with their own agendas and expertise. They constructed their social relations and inevitably, power relations ensue. Power emerges through importance within the social relations of the project and who has the capacity to make the project work. Inevitably, as this research showed, this leads to three levels of contestation between discourses of money, discourses of expertise and knowledge and discourses of legality and regulation imposed by the State. The inability of the stakeholders to reconcile their power relations in dealing with contests between ownership, goals, design and construction delivery has led in all three cases to additional time being used to negotiate solutions, overcome the contest between the pragmatic solutions offered by experts, architects, engineers, builders, suppliers, and so on, and the discourses of money embedded in the behaviours of owners. The systems used, including design-bid-build in all three cases, did not affect the lack of reconciling. In these cases, there was often reference to the 'nuisance' type stakeholder. This was not structural, rather it was behavioural, suggesting Foucault's importance on the 'way we see ourselves' as being significant in the social relations we create. The case studies all showed that these 'nuisance' derived social relations negatively affected the progress of each. In each of the case studies, these contests and subsequent delays had led to cost overruns, poor working relationships, project delays, and often poorer quality of materials used in many instances where compromises had to be made.

The initial stages of this research were informed by an argument that stakeholder's power and the relationship among stakeholders affect construction projects (Pinto 2000; Sage and Dainty 2012; Cashmore et al. 2014), but their analyses lacked those power relationships being deconstructed and differentiated. This analysis, through deconstruction of the discourse in the three Thai construction projects, highlights another perspective of power and its effects in construction projects. The research differentiates the relativities between stakeholders, highlights the complexities inherent in multiple discourses and demonstrates that power relations change, that perceptions differ and are dynamic, all creating uncertainties and inefficiencies in the construction process, and all contributing to increases in project time, creation of delays, poor working relationships, increased costs and sometimes poor delivery outcomes. The case studies also highlight that the advantages of power relations contestation through conflict resolution resulted in keeping the project on track overall, accepting that someone though could be unhappy as construction is not a zero-sum game. There are always winners and losers. Power relations are important in construction and its impact, where these relationships are strained and can lead to significant additional costs and project delays disadvantaging those controlling the dominant discourse-money. So who is really sitting on the other side of the table in Thai construction projects?

\section{Funding}

This research has been funded by the Royal Thai Embassy, Canberra, through the Asia Institute, University of Melbourne.

\section{ORCID}

Sittimont Kanjanabootra (1) http://orcid.org/0000-0002$7557-4186$

\section{Note}

1. Feng Shui is an understanding of the physical configuration of geographical features, applied to both the macro (e.g. design of a city, selection of site, etc.) and micro (e.g. orientation of building, interior layout, etc.) built environment. Mak and Ng (2005) and Thongkamsamut and Buranakarn (2007).

\section{References}

Akerlof, G.A. (1970) The market for 'Lemons': quality uncertainty and the market mechanism. The Quarterly fournal of Economics, (The MIT Press), 84(3), 488-500.

Austen, S., Seymour, R., Brown, K., Furneaux, C. and McCabe, A. (2008) Multi-outcome Construction Policies, CRC for Construction Innovation, Brisbane.

Ball, S.J. (1990) Politics and Policy Making in EducationExplorations in Policy Sociology, Routledge, London.

Bazeley, P. and Jackson, K. (2013) Qualitative Data Analysis with NVivo, Sage, London.

Boulding, K.E. (1990), Three Faces of Power, Sage, Newbury Park, CA.

Brass, D.J. and Burkhardt, M.E. (1993) Potential power and power use: an investigation of structure and behavior. Academy of Management Fournal, 36(3), 441-70.

Cashmore, M., Richardson, T. and Axelsson, A. (2014) Seeing power in international development cooperation: environmental policy integration and the World Bank. Transactions of the Institute of British Geographers, 39(1), 155-68.

Chou, J-S. and Ongkowijoyo, C.S. (2014) Risk-based group decision making regarding renewable energy schemes 
using a stochastic graphical matrix model. Automation in Construction, 37(January), 98-109.

Cicmil, S., Williams, T., Thomas, J. and Hodgson, D. (2006) Rethinking project management: researching the actuality of projects. International fournal of Project Management, 24 (8), 675-86.

Clegg, S.R. (1989) Frameworks of Power, Sage, London.

Clegg, S.R. (1992) Contracts cause conflicts, in Fenn, P. and Gameson, R. (eds.), Construction conflict management and resolution, E \& F N Spon, London, pp. 128-44.

Clegg, S.R. (2006) The bounds of rationality: power/history/ imagination. Critical Perspectives on Accounting, 17(7), 847-63.

Clegg, S.R., Courpasson, D. and Phillips, N. (2006), Power and Organizations, Pine Forge Press, London.

Corbitt, B.J. (2000) Developing intraorganizational electronic commerce strategy: an ethnographic study. Fournal of Information Technology, 15(2), 119-30.

Corbitt, B.J. and Thanasankit, T. (2002) Acceptance and leadership-Hegemonies of e-commerce policy perspectives. Prometheus, 20(1), 39-57.

Corbitt, B., Peszynski, K., Inthanond, S., Thanasankit, T. and Hill, B. (2004) Cultural differences, information and code systems. Fournal of Global Information Management, 12(3), 65-85.

Dainty, A. (2008) Methodological pluralism in construction management research, in Knight, A. and Ruddock, L. (eds.) Advanced Research Methods in the Built Environment, Blackwell Publishing, Sussex, UK, pp. 1-12.

Donaldson, T. and Preston, L.E. (1995) The stakeholder theory of the corporation: concepts, evidence, and implications. Academy of Management Review, 20(1), 65-91.

Fellows, R. and Liu, A. (2008) Research Methods for Construction, 3rd edn, Blackwell, West Sussex, UK.

Foucault, M. (1977) Discipline and Punish: The Birth of the Prison, Random House LLC, New York.

Foucault, M. (1978) The History of Sexuality, Vol. 1, An Introduction, trans. Robert Hurley, Pantheon, New York.

Foucault, M. (1980) Power/Knowledge: Selected Interviews and Other Writings, 1972-1977, Vintage, New York.

Gerring, J. (2007) Case Study Research: Principles and Practices, Cambridge University Press, Cambridge, UK.

Hampden-Turner, C. and Trompenaars, F. (1997) Riding the Waves of Culture: Understanding Diversity in Global Business, McGraw-Hill, New York.

Hanisch, B. (2009) Exploring the influences of the development and implementation of speech-enabled software on the injury management business processes in an elite sporting club. $\mathrm{PhD}$ thesis. RMIT University.

Hanisch, J. Thanasankit, T. and Corbitt, B. (2001) Exploring the cultural and social impacts on the requirements engineering processes-highlighting some problems challenging virtual team relationships with clients. Fournal of Systems and Information Technology, 5(2), 1-20.

Harquail, C.V. and King, A.W. (2010) Construing organizational identity: the role of embodied cognition. Organization Studies, 31(12), 1619-48.

Hofstede, G. (1980) Culture's Consequences: International Differences in Work-related Values, Sage Publications, Beverly Hills, CA.
Hofstede, G. (1997) Cultures and Organizations: Software of the Mind, 1st edn, McGraw-Hill, New York.

Hofstede, G. (1998) Masculinity and Femininity: The Taboo Dimension of National Cultures, Sage Publications, Thousand Oaks, CA.

Hofstede, G. (2001) Culture's Consequences: Comparing Values, Behaviors, Institutions and Organizations across Nations, 2nd edn, Sage Publications, Thousand Oaks, CA.

Hofstede, G. and Hofstede, G.J. (2005) Cultures and Organizations: Software of the Mind, 2nd edn, McGrawHill, New York.

Hofstede, G.J., Pedersen, P. and Hofstede, G. (2002) Exploring Culture: Exercises, Stories and Synthetic Cultures, Intercultural Press, Boston, MA.

Hofstede, G., Hofstede, G.J. and Minkov, M. (2010) Cultures and Organizations: Software of the Mind, 3rd edn, McGrawHill, New York.

Hohfeld, W.N. (1917) Fundamental legal conceptions as applied in judicial reasoning. The Yale Law fournal, 26(8), 710-70.

Ibrahim, N.H. (2013) Reviewing the evidence: use of digital collaboration technologies in major building and infrastructure projects. ITcon, 18, 40-63.

Jirachiefpattana, W. (1996) The impact of Thai culture on executive information systems development, in Proceedings of the 6th International Conference Theme 1, Globalization: Impact on and Coping Strategies in Thai Society, Chiang Mai, Thailand, 14-17 October, pp. 97-110.

Kanjanabootra, S., Corbitt, B. and Nicholls, M. (2013) Evaluating knowledge management systems efficacy and effectiveness in a design science context. Fournal of Systems and Information Technology, 15(4), 324-46.

Lindebaum, D. and Fielden, S. (2011) It's good to be angry': enacting anger in construction project management to achieve perceived leader effectiveness. Human Relations, 64(3), 437-58.

Love, P., Davis, P., Ellis, J., and Cheung, S.O. (2010) Dispute causation: identification of pathogenic influences in construction. Engineering, Construction and Architectural Management, 17(4), 404-23.

Love, P.E.D., Matthews, J., Simpson, I., Hill, A. and Olatunji, O.A. (2014) A benefits realization management building information modeling framework for asset owners. Automation in Construction, 37(January), 1-10.

Mak, M.Y. and Ng, S.T. (2005) The art and science of Feng Shui-a study on architects' perception. Building and Environment, 40(3), 427-34.

Marshall, N. (2006) Understanding power in project settings, in Hodgson, D. and Cicmil, S. (eds.) Making Project Critical, Palgrave Macmillan, Hampshite, pp. 207-31.

Mitev, N.N. (2001) The social construction of IS failure: symmetry, the sociology of translation and politics, in Adam, A., Howcroft, D., Richardson, H. and Robinson, B. (eds.) Re-defining Critical Research in Information Systems, University of Salford, Salford, pp. 16-34.

Nayaar, P.R. (1990) Information asymmetries: a source of competitive advantage for diversified service firms. Strategic Management fournal, 11(7), 513-19. 
Nguyen, L., Torlina, L., Peszynski, K. and Corbitt, B. (2006) Power relations in virtual communities: an ethnographic study. Electronic Commerce Research, 6(1), 21-37.

Oliomogbe, G. and J Smith, N. (2013) Value in megaprojects. Organization, Technology \& Management in Construction, 4 (Special Issue), 617-24.

Peszynski, K.J. and Corbitt, B.J. (2006) Politics, complexity, and systems implementation: critically exposing power. Social Science Computer Review, 24(3), 326-41.

Pinto, J.K. (2000) Understanding the role of politics in successful project management. International fournal of Project Management, 18(2), 85-91.

Sage, D. and Dainty, A. (2012) Understanding power within project work: the neglected role of material and embodied registers. Engineering Project Organization fournal, 2(4), 202-15.

Sage, D., Dainty, A. and Brookes, N. (2010) Who reads the project file? Exploring the power effects of knowledge tools in construction project management. Construction Management and Economics, 28(6), 629-39.

Schweber, L. and Leiringer, R. (2012) Beyond the technical: a snapshot of energy and buildings research. Building Research E Information, 40(4), 481-92.

Spence, M. (1973) Job market signaling. Quarterly fournal of Economics, (The MIT Press), 87(3), 355-74.

Stake, R.E. (1985) Case Study, World Yearbook of Education, Kogan Page, London.
Thanasankit, T. (2002) Requirements engineering-exploring the influence of power and Thai values. European Fournal of Information Systems, 11(2), 128-41.

Thanasankit, T. and Corbitt, B. (2000) Cultural context and its impact on requirements elicitation in Thailand. The Electronic Fournal on Information Systems in Developing Countries, 1(January), 1-12.

Thongkamsamut, C. and Buranakarn, V. (2007) Form follows Feng Shui. Nakhara: Fournal of Environmental Design and Planning. 2(November), 37-54.

Walker, A. and Newcombe, R. (2000) The positive use of power on a major construction project. Construction Management and Economics, 18(1), 37-44.

Walker, D.H. and Shen, Y.J. (2002) Project understanding, planning, flexibility of management action and construction time performance: two Australian case studies. Construction Management $\mathcal{G}$ Economics, 20(1), 31-44.

Weber, M. (1978). Economy and Society: An Outline of Interpretive Sociology, Roth, G. and Wittich, C. (ed.), University of California Press, Berkeley.

Williams, M. (2000) Interpretivism and Generalisation. Sociology, 34(2), 209-24.

Yin, R.K. (1994) Case Study Research, SAGE, Thousand Oaks, CA.

Zou, P., Zhang, G. and Wang, J. (2007) Understanding the key risks in construction projects in China. International Fournal of Project Management, 25(6), 601-14. 